\title{
New bacterial growth in bronchial secretions after bronchoscopic valve implantation
}

This article was published in the following Dove Press journal:

International Journal of COPD

\author{
Nilab Sarmand' \\ Daniela Gompelmann ${ }^{1,2}$ \\ Konstantina Kontogianni' \\ Markus Polke' \\ Felix JF Herth ${ }^{1,2}$ \\ Ralf Eberhardt ${ }^{1,2}$ \\ 'Department of Pulmonology \\ and Respiratory Care Medicine, \\ Thoraxklinik, at the University of \\ Heidelberg, Heidelberg, ${ }^{2}$ Translational \\ Lung Research Center Heidelberg, \\ Member of the German Center for \\ Lung Research DZL, at the University \\ of Heidelberg, Heidelberg, Germany
}

Correspondence: Nilab Sarmand Department of Pulmonology and Respiratory Care Medicine, Thoraxklinik University of Heidelberg, Roentgenstr I, 69126 Heidelberg, Germany

$\mathrm{Tel}+496221396 \quad 200$

Fax $+49622 I 396 \quad 202$

Email nilab.sarmand@med.uniheidelberg.de

\begin{abstract}
Background: Bronchoscopic valve implantation is an established treatment in selected patients with severe lung emphysema. There is evidence in literature of increased bacterial colonization of various implants. So far, it is unclear if an increased bacterial colonization can also be observed after endoscopic valve therapy.
\end{abstract}

Methods: Retrospective analysis of patients with examination of the bronchial secretions for presence or change of bacterial growth before and after valve implantation.

Results: Overall, 144 patients who underwent bronchoscopic follow-up after valve implantation were included in this analysis. Prior to valve placement, only 7 out of 144 consecutive emphysema patients (5\%) presented with evidence of bacterial colonization, whereas 137 patients (95\%) showed no bacterial growth prior to valve placement. One hundred seven out of the 137 patients (78\%) showed new bacterial growth after valve implantation. Almost 38\% of the patients who presented with a new bacterial growth had evidence of Viridans streptococci, Rothia mucilaginousa and Neisseria species simultaneously, as bacterial colonization. Pathogenic bacterial growth was recorded for Staphylococcus aureus (18\%), Pseudomonas aeruginosa (13\%) and Stenotrophomonas maltophilia (9\%) microorganisms. There was also a significant bacterial growth by Moraxella catarrhalis (26\%) and anaerobic bacteria (23\%), especially in patients with complete atelectasis after successful endoscopic lung volume reduction. For all of the 7 patients, the presented initial bacterial colonization showed a change in the flora after bronchoscopy valve implantation.

Conclusion: In this study we observed an increased bacterial colonization in the long term after valve implantation. This finding needs further evaluation regarding its possible clinical relevance but should be taken into consideration in the follow-up of these patients.

Keywords: valve implantation, lung volume reduction, bacterial growth, COPD

\section{Background}

COPD is a widespread disease. Around 65 million people suffer from a moderate-tosevere COPD. ${ }^{1}$ Severe COPD often presents with lung emphysema caused by extensive destruction of the alveolar walls and thus resulting in hyperinflation and airspace enlargement. ${ }^{2}$ Endoscopic lung volume reduction (ELVR) such as valve implantation is an established treatment in selected patients with severe lung emphysema. ${ }^{3}$ Thereby, one-way valves are placed in the airways of the most emphysematous lung lobe using fiberoptic bronchoscopy. ${ }^{4}$ The result of valve implantation is blocking ventilation and thus inducing atelectasis of the hyperinflated lobe. ${ }^{5}$ However, various complications are reported after endoscopic valve placement including pneumothorax, pneumonia, recurrent exacerbations and increased sputum production. ${ }^{6}$

Exacerbations are defined by an increase from baseline in dyspnea, sputum volume and sputum purulence. Most of the acute exacerbations in advanced COPD triggered 
by bacteria are caused by Haemophilus influenzae, Moraxella catarrhalis, Streptococcus pneumoniae and Pseudomonas aeruginosa. ${ }^{7}$ The course of the COPD is complicated by recurrent exacerbations. ${ }^{1}$ There is evidence that acute exacerbations are related to bacterial growth. ${ }^{8}$ Nevertheless, there are nonpathogenic microorganisms such as Streptococcus viridans, Neisseria spp., Corynebacterium spp. and Candida spp. belonging to the oropharyngeal or gastrointestinal flora, which usually do not cause respiratory infections. Pathogenic microorganisms involved in respiratory infections are $P$. aeruginosa, Haemophilus influenzae, M. catarrhalis, Streptococcus pneumoniae, Klebsiella pneumoniae and Staphylococcus aureus. ${ }^{9}$

Previous studies have shown that patients with COPD have bacterial infections in the lower airways. However, these findings provide strong evidence that there is no significant risk of exacerbation caused by Streptococcus pneumoniae and $M$. catarrhalis. In comparison, bacterial growth with P. aeruginosa and Haemophilus influenzae was associated with increased rate of acute exacerbations in patients with COPD. ${ }^{10}$

Very little data are available regarding the association between bacterial growth after valve implantation and procedure-related COPD exacerbation. ${ }^{11}$ This retrospective analysis investigates the bacterial growth with examination of the bronchial secretions for presence or change of bacterial growth before and after valve implantation.

\section{Methods}

Data were retrospectively collected from patients with severe COPD and emphysema who underwent an endoscopic valve implantation procedure in the Thoraxklinik Heidelberg between January 2011 and December 2014. In this analysis, examinations of the bronchial secretion for presence or change of bacterial growth before and after valve implantation were assessed. The protocol of this trial was approved by the local ethics committee of Heidelberg (S-609/2012). All patients gave consent for scientific use of the data acquired when they were admitted to our hospital. As the data were retrospectively analyzed, no further patient consent was required.

\section{Subjects enrollment}

All patients with the diagnosis of COPD and severe lung emphysema who received endoscopic placement of endobronchial (EBV; Pulmonx, Neuchâtel, Switzerland) and/ or intrabronchial valves (Olympus, Tokyo, Japan), and in whom bronchial secretion was assessed before and after valve therapy, were enrolled in this analysis. Patients with no endoscopic follow-up after valve implantation were excluded. Each patient was only included once in the analysis. Prior to valve implantation, all patients underwent multidetector computed tomography (MDCT) to identify the most emphysematous lung lobe. To quantify interlobar collateral ventilation that predicts therapeutic outcome, CT fissure analysis and/or catheter-based Chartis ${ }^{\circledR 12}$ measurement were performed.

Demographic variables (Table 1) and presence or absence of atelectasis within MDCT after valve implantation were collected. Bronchial secretion samples were examined from the treated lobe for presence or change of bacterial growth before and after valve implantation. Each bacterial organism in the bronchial secretion was recorded.

\section{Assessment of clinical data}

The data were collected by reviewing lung function parameters (vital capacity, forced expiratory volume in 1 second $\left[\mathrm{FEV}_{1}\right]$, residual volume $[\mathrm{RV}]$, total lung capacity), exercise test (6-minute-walk test) and dyspnea score (modified Medical Research Council) from each patient prior to valve placement.

\section{Bronchial secretion samples}

Bronchial secretion samples (aspiration of bronchial secretion from the treated lobe after instillation of $20 \mathrm{~mL}$ saline fluid) were obtained before and after valve implantation and in each bronchoscopic follow-up. Every patient underwent

Table I Baseline demographics

\begin{tabular}{ll}
\hline $\begin{array}{l}\text { Demographic } \\
\text { parameters }\end{array}$ & $\begin{array}{l}\text { Baseline } \\
(\mathbf{n}=\mathbf{1 4 4})\end{array}$ \\
\hline Gender (\% female) & 47.2 \\
Age (years) & $63.3 \pm 7.2$ \\
BMI (kg/m $)$ & $23.8 \pm 4.6$ \\
VC (L) & $2.4 \pm 0.8$ \\
VC (\%) & $69.2 \pm 17.3$ \\
FEV,$(L)$ & $0.8 \pm 0.2$ \\
FEV $(\%)$ & $29.6 \pm 7.2$ \\
RV (L) & $5.8 \pm 1.3$ \\
RV (\%) & $267.1 \pm 59.2$ \\
TLC (L) & $8.2 \pm 1.5$ \\
TLC (\%) & $141.2 \pm 21.5$ \\
DLCO SB (\%) & $33.9 \pm 11.0$ \\
DLCO/VA (\%) & $49.0 \pm 16.4$ \\
6-MWD (m) & $284.4 \pm 99.3$ \\
mMRC & $2.8 \pm 1.1$ \\
\hline
\end{tabular}

Abbreviations: BMI, body mass index; DLCO, diffusing capacity of the lungs for carbon monoxide; DLCO SB, single-breath diffusing capacity of the lung for carbon monoxide; $\mathrm{FEV}_{1}$, forced expiratory volume in I second; mMRC, modified Medical Research Council; 6-MWD, 6-minute walk distance; RV, residual volume; TLC, total lung capacity; VA, alveolar volume; VC, vital capacity. 
a bronchoscopic follow-up within 12 months, from 12 to 24 months, and after 24 months. The indication for bronchoscopic follow-up was an increased productive cough, and lack or loss of success assuming valve malfunction.

Bronchial secretion was examined for bacterial and fungal growth. The airway bacteria cultures were classified into potential pathogenic microorganisms and nonpotential pathogenic microorganisms. Samples were processed by the clinical microbiology laboratory using standard procedures. Cultures were incubated and the number of visible colonies was recorded. Bacterial growth was examined based on macroscopic and microscopic methods.

\section{Statistical analysis}

Categorical variables are presented as mean $\pm \mathrm{SD}$, minimum and maximum or $\mathrm{n}$ and $\%$ for frequency data.

\section{Results}

Overall, 397 patients with severe COPD and emphysema underwent endoscopic valve implantation in the Thoraxklinik University of Heidelberg from January 2011 to December 2014. Out of these, 253 patients had no further bronchoscopy because there was no suspected valve malfunction on the MDCT or they did not return for follow-up. Another exclusion criteria for this present analysis was the absence of bronchial secretion examination prior to valve implantation. Therefore, the final analysis involved 144 patients. All these patients (mean age was $63 \pm 7$ years) had severe COPD with a mean $\mathrm{FEV}_{1}$ of $0.81 \pm 0.21$ (1), and the mean RV was $267 \% \pm 59 \%$ predicted. The baseline demographics are presented in Table 1.

Out of the 144 patients, only 7 subjects (5\%) had evidence of bacterial colonization in the bronchial secretion, whereas 137 subjects (95\%) showed no bacterial growth at baseline before valve implantation. The patients with bacterial colonization prior to treatment showed nonpotential pathogenic microorganisms in the bronchial secretions. All patients had an endoscopic follow-up after valve implantation after 12 months, 53 of these included patients had a further bronchoscopie after 12 to 24 months and 32 patients were performed an additional bronchoscopy after 24 months because of suspected valve malfunction or migration of the valves according to the MDCT. Patients who had an increased sputum production also had another bronchoscopy for bronchial secretion examination.

Patients who had valves implanted did show new bacterial growth. Almost 38\% of the patients who presented with new bacterial growth had evidence of Viridans streptococci, Rothia mucilaginosa and Neisseria spp. simultaneously, as bacterial colonization. Pathogenic bacterial growth was recorded for Staphylococcus aureus (18\%), P. aeruginosa (13\%) and Stenotrophomonas maltophilia (9\%) microorganisms. There was also a significant bacterial growth by $M$. catarrhalis (26\%) and anaerobic bacteria (23\%) (Table 2). All of the 7 patients who presented with initial bacterial colonization showed a change in the flora after valve implantation.

Out of the 137 patients 35 patients had a lobar atelectasis and 33 patients a partial atelectasis, and the remaining 69 patients had no atelectasis at all. In the assessment of the variability of the absence and presence of atelectasis and microbiologic characteristics, differences were found between total atelectasis after valve implantation but only minimal changes were observed in the prevalence of bacterial growth according to partial atelectasis and absence of atelectasis. The difference was in anaerobic bacteria growth within bronchial secretion samples of patients who developed lobar atelectasis following valve implantation. About $63 \%$ of the 35 patients with lobar atelectasis showed a change in the bacterial growth by evidence of anaerobic bacterial growth after valve implantation (Table 3).

\section{Discussion}

This current retrospective analysis showed an increased and changed bacterial colonization in the long term after endoscopic valve implantation. This analysis illustrated 3 key findings. Firstly, patients who had valves implanted for periods longer than a year showed new bacterial growth. Secondly, the predominant potential pathogenic microorganisms recorded were Staphylococcus aureus and P. aeruginosa. Thirdly, patients with atelectasis after valve implantation

Table 2 New bacterial growth after valve implantation

\begin{tabular}{|c|c|c|c|c|}
\hline & $\begin{array}{l}\text { I } 2 \text { months } \\
(n=137)(\%)\end{array}$ & $\begin{array}{l}\text { I 2-24 months } \\
(n=53)(\%)\end{array}$ & $\begin{array}{l}24 \text { months } \\
(n=32)(\%)\end{array}$ & $\begin{array}{l}\text { Total } \\
(n=137)(\%)\end{array}$ \\
\hline Stenotrophomonas maltophiliae & $7(9)$ & $4(7.5)$ & $2(6)$ & $13(9.5)$ \\
\hline Pseudomonas aeruginosa & $18(13)$ & $3(6)$ & I (3) & $18(13)$ \\
\hline Staphylococcus aureus & $18(13)$ & $4(7.5)$ & $2(6)$ & $24(17.5)$ \\
\hline Moraxella catarrhalis & $36(26)$ & $9(17)$ & $7(22)$ & $52(38)$ \\
\hline Anaerobic bacteria & $22(23)$ & I (2) & I (3) & $24(17.5)$ \\
\hline Fungal growth & $10(7)$ & $4(7.5)$ & $4(12.5)$ & $18(13)$ \\
\hline
\end{tabular}


Table 3 Bacterial growth according to absence and presence of atelectasis

\begin{tabular}{|c|c|c|c|c|}
\hline & $\begin{array}{l}\text { Atelectasis } \\
(n=35)(\%)\end{array}$ & $\begin{array}{l}\text { Partial atelectasis } \\
(n=33)(\%)\end{array}$ & $\begin{array}{l}\text { No atelectasis } \\
(n=69)(\%)\end{array}$ & $\begin{array}{l}\text { Total } \\
(n=137)(\%)\end{array}$ \\
\hline Stenotrophomonas maltophiliae & $2(6)$ & I (3) & $9(12)$ & $13(9)$ \\
\hline Pseudomonas aeruginosa & $4(12)$ & $6(18)$ & $8(10)$ & $18(13)$ \\
\hline Staphylococcus aureus & $5(15)$ & $10(30)$ & $9(13)$ & $24(18)$ \\
\hline Moraxella catarrhalis & $5(15)$ & $5(15)$ & $4(6)$ & $14(10)$ \\
\hline Anaerobic bacteria & $22(63)$ & I (3) & I (I) & $24(17.5)$ \\
\hline
\end{tabular}

showed a change in the bacterial growth by evidence of anaerobic bacterial growth. Therefore, the hypoventilation of the lobar atelectasis because of valve placement can give rise to significantly different bacterial colonization.

Bacterial colonization in the airways may be important to the understanding of COPD. Many studies point out that bacterial colonization influences the rates of COPD exacerbations. ${ }^{13}$ Rosell at al could show that $25 \%$ in a cohort of patients with COPD are colonized by potentially pathogenic microorganisms. It is known that the growth of potentially pathogenic microorganisms is associated with exacerbations of COPD. Especially, the appearance of $P$. aeruginosa in the lower airway is associated with frequent exacerbations independent of the bacterial load. ${ }^{14}$

Additionally, most ventilator-associated pneumonias are caused by Staphylococcus aureus and P. aeruginosa. ${ }^{15}$ It is known that foreign objects within the airways are associated with an increased risk of pulmonary infections because of retention of secretions and impairment of the mucociliary clearance. The implantation of airway stents, for example, is associated with airway colonization of potentially pathogenic microorganisms. ${ }^{16-18}$ Thereby, Staphylococcus aureus and $P$. aeruginosa are the dominant pathogens for stent-associated respiratory tract infection. ${ }^{17}$ Interestingly, the airway colonization of potentially pathogenic microorganisms did not lead to relevant respiratory infections. ${ }^{18}$

Anaerobic organisms also play an important role in pleuropulmonary infections. Anaerobic bacteria colonize normal oral cavity, upper respiratory tract, gastrointestinal, genital and skin flora. They may cause simple aspiration from acute to severe, necrotizing pneumonias, to chronic infections, such as lung abscess and empyema. ${ }^{19}$ Successful treatment of anaerobic pleuropulmonary infections may need a combined antibiotic therapy and surgical interventions. ${ }^{20}$ Other studies show that anaerobic bacteria frequently colonize the lower respiratory tract of mechanically ventilated patients and they emphasize the importance of the anaerobic bacteria in ventilatory acquired pneumonia. . $^{21,22}$
This retrospective analysis confirmed the hypothesis that valves presenting a foreign object within the airways increase the bacterial airway colonization. We found out that there is a change in bacterial growth after bronchoscopic valve implantation, namely anaerobic bacteria, especially in patients with total atelectasis after valve implantation. Thus, this could mean a higher risk for exacerbation rates of COPD in these patients. ${ }^{23}$ There is evidence in the literature that colonization with $P$. aeruginosa is related to increased rates of COPD exacerbation after EBV implantation..$^{24}$ In this current analysis, the exacerbation frequency was not evaluated. However, only 1 out of 5 randomized controlled trials (RCTs) that compared complete occlusion of the lung lobe by valves to standard therapy reported a statistically significant increased rate of COPD exacerbation with hospitalization within 90 days following valve placement. ${ }^{25-29}$ However, it is questionable, if the increased exacerbation frequency is primarily due to the valves and the bacterial colonization or due to the bronchoscopic procedure itself. In the remaining $4 \mathrm{RCTs}$, no statistically significant difference of the COPD exacerbation rate was found between the treatment and the control groups. However, it must be noted that the follow-up period of these RCTs comprised only 6 months.

In a retrospective analysis, Fuehner et al could show an increased bacterial colonization after lung transplantation (LTX) in patients who had undergone previous ELVR. However, there were no different outcomes after LTX in terms of LTX waiting list time, duration of LTX procedure, ventilatory support, intensive care unit stay after LTX, or time to hospital discharge, comparing patients with previous ELVR to non-ELVR patients. ${ }^{11}$

It is recommended that patients receive a prophylactic antibiotic therapy as well as short courses of oral steroids after valve implantation, to prevent bronchitis and exacerbations. ${ }^{30}$ The patients in the analyzed cohort also received a prophylactic antibiotic therapy with Cefuroxim after valve implantation, for 5 days, but no oral steroids routinely. However, this recommendation needs further investigation to find out the 
necessity of prophylactic antibiotic therapy and oral steroid therapy, as well as their influence on the bacterial airway colonization.

Recognized limitations of our study are the retrospective design on selected patients and the absence of a control group of patients who had not had valve implantation. Moreover, we did not assess the new bacterial growth for its possible clinical relevance and exacerbation rate of COPD. This finding needs further evaluation in prospective trials. As it was a retrospective analysis, only patients who underwent another bronchoscopy after valve implantation were enrolled, including patients who complained about increased mucus or experienced lack or loss of benefit from the implantation. This means that patients without symptoms, but still colonized, were not recorded leading to selection bias. Furthermore, the follow-up bronchoscopy was performed at different times after valve placement, so that a time-based structured detailed analysis was not possible.

\section{Conclusion}

In summary, these results underline the need to consider, both the bacterial colonization and exacerbations of COPD. By assuming that airways can harbor both generalized areas of nonpathogenic microbiome and a single site containing a potential pathogenic colonization, our results suggest potential progress in disease even in the absence of exacerbations in patients who have undergone bronchoscopic valve implantation. Nevertheless, knowledge of different colonization patterns may be important for future antibiotic strategies and when exacerbations occur in patients after bronchoscopic valve implantation.

\section{Disclosure}

The authors report no conflicts of interest in this work.

\section{References}

1. Vogelmeier CF, Criner GJ, Martinez FJ, et al. Global strategy for the diagnosis, management, and prevention of chronic obstructive lung disease 2017 report: GOLD executive summary. Eur Respir J. 2017;49(3): 1700214.

2. William MacNee. ABC of chronic obstructive pulmonary disease, Pathology, pathogenesis, and pathophysiology. BMJ. 2006;332(7551): 1202-1204.

3. Shah PL, Herth FJ. Current status of bronchoscopic lung volume reduction with endobronchial valves. Thorax. 2014;69(3): 280-286.

4. Valipour A, Herth FJ, Burghuber OC, et al. Target lobe volume reduction and COPD outcome measures after endobronchial valve therapy. Eur Respir J. 2014;43(2):387-396.

5. Klooster K, Nick HT, Hacken T, et al. Endobronchial valves for emphysema without interlobar collateral ventilation. N Engl J Med. 2015;373: 2325-2335.
6. Slebos DJ, Shah PL, Herth FJ, Valipour A. Endobronchial valves for endoscopic lung volume reduction: best practice recommendations from expert panel on endoscopic lung volume reduction. Respiration. 2017;93(2): $138-150$.

7. Cabello H, Torres A, Celis R, et al. Bacterial colonization of distal airways in healthy subjects and chronic lung disease: a bronchoscopic study. Eur Respir J. 1997;10(5):1137-1144.

8. Sapey E, Stockley RA. COPD exacerbations. 2: aetiology. Thorax. 2006; 61(3):250-258.

9. Zalacain R, Sobradillo V, Amilibia J, et al. Predisposing factors to bacterial colonization in chronic obstructive pulmonary disease. Eur Respir J. 1999;13(2):343-348.

10. Leung JM, Tiew PY, Mac Aogáin M, et al. The role of acute and chronic respiratory colonization and infections in the pathogenesis of COPD. Respirology. 2017;22(4):634-650.

11. Fuehner T, Clajus C, Fuge J, et al. Lung transplantation after endoscopic lung volume reduction. Respiration. 2015;90(3):243-250.

12. Koster TD, van Rikxoort EM, Huebner RH, et al. Predicting lung volume reduction after endobronchial valve therapy is maximized using a combination of diagnostic tools. Respiration. 2016;92(3): $150-157$.

13. Patel IS, Seemungal TA, Wilks M, Lloyd-Owen SJ, Donaldson GC, Wedzicha JA. Relationship between bacterial colonisation and the frequency, character, and severity of COPD exacerbations. Thorax. 2002; 57(9):759-764.

14. Rosell A, Monsó E, Soler N, et al. Microbiologic determinants of exacerbation in chronic obstructive pulmonary disease. Arch Intern Med. 2005;165(8):891-897.

15. Crnich CJ, Safdar N, Maki DG. The role of the intensive care unit environment in the pathogenesis and prevention of ventilatorassociated pneumonia. Respir Care. 2005;50(6):813-836; discussion 836-838.

16. Grosu HB, Eapen GA, Morice RC, et al. Stents are associated with increased risk of respiratory infections in patients undergoing airway interventions for malignant airways disease. Chest. 2013;144(2): 441-449.

17. Noppen M, Piérard D, Meysman M, Claes I, Vincken W. Bacterial colonization of central airways after stenting. Am J Respir Crit Care Med. 1999;160(2):672-677.

18. Agrafiotis M, Siempos II, Falagas ME. Infections related to airway stenting: a systematic review. Respiration. 2009;78(1):69-74.

19. Bartlett JG. Anaerobic bacterial infections of the lung and pleural space. Clin InfectDis. 1993;16(Suppl 4):S248-S255.

20. Verma P. Laboratory diagnosis of anaerobic pleuropulmonary infections. Semin Respir Infect. 2000;15(2):114-118.

21. Robert R, Grollier G, Frat JP, et al. Colonization of lower respiratory tract with anaerobic bacteria in mechanically ventilated patients. Intensive Care Med. 2003;29(7):1062-1068.

22. Marik PE, Careau P. The role of anaerobes in patients with ventilatorassociated pneumonia and aspiration pneumonia: a prospective study. Chest. 1999;115(1):178-183.

23. Fruchter O, Rosengarten D, Goldberg E, Ben-Zvi H, Tor R, Kramer MR. Airway bacterial colonization and serum C-reactive protein are associated with chronic obstructive pulmonary disease exacerbation following bronchoscopic lung volume reduction. Clin Respir J. 2016;10(2): 239-245.

24. Tuleta I, Pizarro C, Molitor E, Kristiansen G, Nickenig G, Skowasch D. Recurrent chronic obstructive pulmonary disease exacerbations after endobronchial valve implantation are associated with the presence of Pseudomonas aeruginosa. Respiration. 2016;91(6):510-516.

25. Sciurba FC, Ernst A, Herth FJ, et al; VENT Study Research Group. A randomized study of endobronchial valves for advanced emphysema. N Engl J Med. 2010;363(13):1233-1244.

26. Herth FJ, Noppen M, Valipor A, et al; International VENT Study Group. Efficacy predictors of lung volume reduction with Zephyr valves in a European cohort. Eur Respir J. 2012;39(6):1334-1342. 
27. Davey C, Zoumut Z, Jordan S, et al. Bronchoscopic lung volume reduction with endobronchial valves for patients with heterogeneous emphysema and intact interlobar fissures (the BelLieVeR-HIFi study): a randomised controlled trial. Lancet. 2015;386(9998): 1066-1073.

28. Klooster K, ten Hacken NH, Hartman JE, Kerstjens HA, van Rikxoort EM, Slebos DJ. Endobronchial valves for emphysema without interlobar collateral ventilation. $N$ Engl J Med. 2015;373(24):2325-2335.
29. Valipour A, Slebos DJ, Herth F, et al; IMPACT Study Team. Endobronchial valve therapy in patients with homogeneous emphysema. Results from the IMPACT Study. Am J Respir Crit Care Med. 2016; 194(9):1073-1082.

30. Slebos DJ, Shah PL, Herth FJ, Valipour A. Endobronchial valves for endoscopic lung volume reduction: best practice recommendations from expert panel on endoscopic lung volume reduction. Respiration. 2017;93(2):138-150

\section{Publish your work in this journal}

The International Journal of COPD is an international, peer-reviewed journal of therapeutics and pharmacology focusing on concise rapid reporting of clinical studies and reviews in COPD. Special focus is given to the pathophysiological processes underlying the disease, intervention programs, patient focused education, and self management protocols.

\section{Dovepress}

This journal is indexed on PubMed Central, MedLine and CAS. The manuscript management system is completely online and includes a very quick and fair peer-review system, which is all easy to use. Visit http://www.dovepress.com/testimonials.php to read real quotes from published authors.

Submit your manuscript here: http://www.dovepress.com/international-journal-of-chronic-obstructive-pulmonary-disease-journal 